\title{
A New Method to Optimize the Wake Flow of a Vehicle: The Leading Edge Rotating Cylinder
}

\author{
Nan Shao, ${ }^{1}$ Guofeng Yao, ${ }^{1}$ Chang Zhang, ${ }^{2}$ and Min Wang ${ }^{1}$ \\ ${ }^{1}$ Mechanical Department, Jilin University, Nanling Campus, Changchun 130025, China \\ ${ }^{2}$ China FAW Group Corporation R\&D Center, Changchun 130011, China \\ Correspondence should be addressed to Guofeng Yao; yaogf@jlu.edu.cn
}

Received 16 February 2017; Revised 17 April 2017; Accepted 21 May 2017; Published 28 June 2017

Academic Editor: Sébastien Poncet

Copyright (c) 2017 Nan Shao et al. This is an open access article distributed under the Creative Commons Attribution License, which permits unrestricted use, distribution, and reproduction in any medium, provided the original work is properly cited.

\begin{abstract}
The wake flow of a vehicle significantly influences its aerodynamic performance and the stability during high-speed drive. Therefore, optimization of the vehicle wake flow is an effective way to improve its aerodynamic performance and further improve the handling stability and fuel economy. In this paper, a new method, the leading edge rotating cylinder, is used to optimize the wake flow of a vehicle. According to the results of simulations, this method can reduce the pressure drag, increase the negative lift force, and strengthen the stability of the vehicle under crosswind. Furthermore, this method optimizes not only the wake flow of the vehicle with rotating cylinders but also the interactive vehicles in the driving route in overtaking maneuvers or platoon driving. In conclusion, this method effectively optimizes the flow fields around the vehicles, and it significantly helps to improve the handling stability and fuel economy of the vehicle.
\end{abstract}

\section{Introduction}

When a vehicle is driven at high speed, the wake flow influences many elements of its performance. In other words, wake flow optimization is an effective method to improve the performances of a vehicle.

The methods of the wake flow optimization can be divided into two categories: passive control methods and active control methods. One of the passive control methods is to change the appearance of the tail. Ouyang et al.s [1] research verified that the change of the tail edge angle is an effective way to optimize the lift and drag force. One of the passive control methods is to fix flaps to the tail edges [2]. Fixing flaps to different edges arouses different changes of wake flow, which generates different influences to the lift and drag force. Another common passive control method is to fix air deflectors to the surface of the tail [3]. By changing the direction and the angle of the air deflectors, the velocity and structure of the wake flow can be changed. The advantages of passive control methods lie in its low cost and easy implementation. However, the optimizing effect of the wake flow can be further improved. As a result, the active control method was put forward. For example, a blower can be installed to the tail to optimize the wake flow [4]. There have been some other active control methods used to optimize the wake flow.

In this paper, a new active control method called the leading edge rotating cylinder method is used to optimize the wake flow of a vehicle. The theoretical research of the rotating cylinder was conducted by Konstantinidis and Bouris [5], which has been proved to be able to cause the change of the flow fields. The applications of the leading edge rotating cylinder mostly focus on optimizing the outer flow fields of planes. Zhang et al. [6, 7] optimized the flow fields around an airfoil with leading edge rotating cylinder through CFD simulation and obtained favorable results. Then, Lopes et al. [8] visualized the optimization results of the leading edge rotating cylinder by smoke flow method in laboratory, which confirms the validity of this method. Badry et al. [9] installed a pair of rotating cylinders to the edge of a lifting body to optimize the outer flow fields, which enhances the lift force coefficient and reduces the drag force coefficient.

In this paper, a pair of leading edge rotating cylinders are installed to the tail of a bus to optimize the wake flow. This method can reduce the pressure drag, increase the 


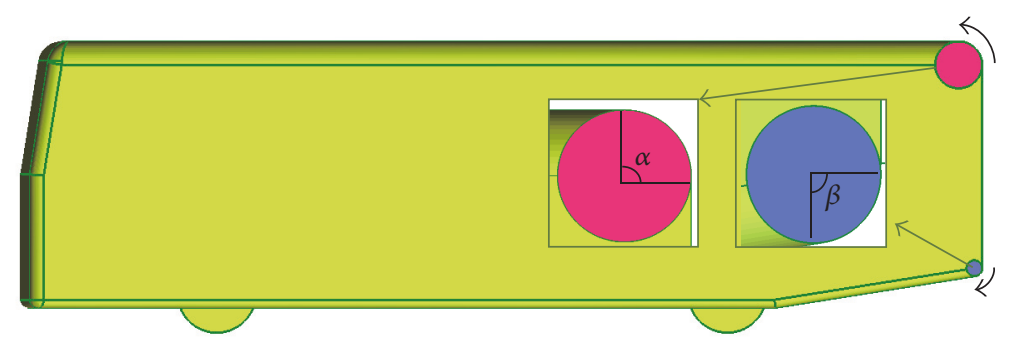

(a)



(b)

FIgure 1: The bus model with cylinders.

TABLE 1: The major dimensions of bus.

\begin{tabular}{lc}
\hline Length $(\mathrm{m})$ & 12.000 \\
Width $(\mathrm{m})$ & 2.500 \\
Height $(\mathrm{m})$ & 3.400 \\
Frontal Area $\left(\mathrm{m}^{2}\right)$ & 9.300 \\
Side Area $\left(\mathrm{m}^{2}\right)$ & 45.600 \\
Wheel base between front and back axles $(\mathrm{m})$ & 6.400 \\
Radius of the cylinder at the upper leading edge of tail $(\mathrm{m})$ & 0.300 \\
Radius of the cylinder at the lower leading edge of tail $(\mathrm{m})$ & 0.100 \\
$\alpha$ in Figure 1 (degree) & 90 \\
$\beta$ in Figure 1 (degree) & 80.9 \\
Length of the upper cylinder $(\mathrm{m})$ & 1.900 \\
Length of the lower cylinder $(\mathrm{m})$ & 2.300 \\
\hline
\end{tabular}

negative lift force, and strengthen the vehicle stability under crosswind. Furthermore, this method optimizes not only the wake flow of the vehicle with rotating cylinders but also the interactive vehicles without cylinders in the driving route in overtaking maneuvers or platoon driving. This method effectively optimizes the flow fields around the vehicles, and it significantly helps to improve the handling stability and fuel economy of the vehicle.

\section{Description of the Bus Model}

The bus model adopted in this simulation is shown in Figure 1. This model is chosen because of its simple appearance with typical characters of a common bus, and it has been widely investigated in the aerodynamic fields [10-12]. The model dimensions shown in Table 1 come from Hoffman et al. [10].

The wake flow structure of this bus is shown in Figure 2; the flows from the upper surface and side surfaces meet in this region and form a pair of counterrotating trailing vortices. Similarly, the flows from the lower surface and side surfaces meet in this region and form another pair of counterrotating trailing vortices. Because of the gravity, the lower pair of vortices firstly disappears during the interaction with ground.

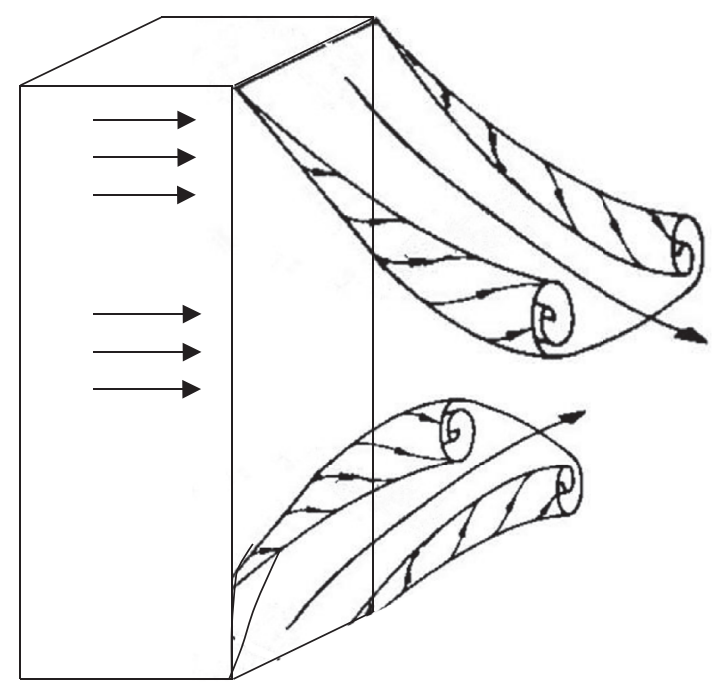

FIGURE 2: Wake flow structure of bus.

As a result, the upper pair of vortices is the major factor that influences the aerodynamic forces.

Because the trailing vortices are the major factors that generate the pressure drag, trailing vortices should be avoided in reducing the drag force. There are three methods to avoid the formation of the trailing vortices:

(1) The flow from the upper and side surface should be avoided to meet in the tail region.

(2) The flow from the lower surface should not roll up.

(3) The trailing vortices should be away from the tail as far as possible [12].

According to the methods above, a pair of rotating cylinders are installed to the upper and lower edge. The rotating directions of the cylinders are shown in Figure 1, which can decelerate the flow from the upper and lower surface. As a result, the position where the flows from the upper and lower surfaces meet will move backward, which makes the trailing vortices further away from the tail. 




FIgURE 3: The computational domain and the mesh density.

The mathematical model of the aerodynamic coefficients is shown in the following formula:

$$
\begin{gathered}
C_{d}=\frac{2 D}{\rho S V^{2}}, \\
C_{y}=\frac{2 Y}{\rho S V^{2}}, \\
C_{l}=\frac{2 L}{\rho S V^{2}}, \\
C_{m}=\frac{2 N}{\rho l S V^{2}}, \\
C_{\mathrm{pm}}=\frac{2 P}{\rho l S V^{2}},
\end{gathered}
$$

where $C_{d}, C_{y}, C_{l}, C_{m}$, and $C_{\mathrm{pm}}$ are the drag force coefficient, side force coefficient, lift force coefficient, yaw moment coefficient, and pitching moment coefficient, respectively. $\rho$ is the air density, $S$ is the body frontal area, $l$ is the wheel base which is the distance between front and back axles, and $V$ is the steady velocity. Correspondingly, $D, Y, L, N$, and $P$ are the drag force, side force, lift force, yaw moment, and the pitching moment obtained by integrating the pressure and skin friction coefficients over the vehicle surface, respectively, which is shown in the following formula:

$$
\begin{aligned}
C_{p} & =\frac{p-p_{\infty}}{q_{\infty}}, \\
c_{f} & \equiv \frac{\tau}{q_{\infty}},
\end{aligned}
$$

where $p$ and $\tau$ are the pressure and shear stress on the vehicle surface, $p_{\infty}$ is the freestream pressure which is set to 0 , and $q_{\infty}$ is the freestream dynamic pressure which is shown in the following formula:

$$
q_{\infty} \equiv \frac{1}{2} \rho V_{\infty}^{2}
$$

\section{Design of the Simulation}

3.1. Mesh Generation. According to the characteristics of the shape of the bus, a rectangular computational domain is adopted. In order to determine the dimensions of the
Table 2: Aerodynamical coefficients in different blockage ratio.

\begin{tabular}{lccc}
\hline $\begin{array}{l}\text { Blockage } \\
\text { ratio }\end{array}$ & $\begin{array}{c}\text { Dimensions of } \\
\text { computation domain }\end{array}$ & $C_{d}$ & $C_{l}$ \\
\hline $3.1 \%$ & $12 L \times 7 W \times 5 H$ & 0.422 & -0.510 \\
$2.5 \%$ & $12 L \times 8 W \times 5.5 H$ & 0.417 & -0.501 \\
$2.0 \%$ & $12 L \times 9 W \times 6 H$ & 0.402 & -0.422 \\
$1.7 \%$ & $12 L \times 10 W \times 6.5 H$ & 0.393 & -0.341 \\
$1.4 \%$ & $12 L \times 11 W \times 7 H$ & 0.390 & -0.313 \\
$1.2 \%$ & $12 L \times 12 W \times 7.5 H$ & 0.384 & -0.303 \\
$1.1 \%$ & $12 L \times 13 W \times 8 H$ & 0.381 & -0.294 \\
$0.9 \%$ & $12 L \times 14 W \times 8.5 H$ & 0.380 & -0.291 \\
$0.8 \%$ & $12 L \times 15 W \times 9 H$ & 0.380 & -0.290 \\
\hline
\end{tabular}

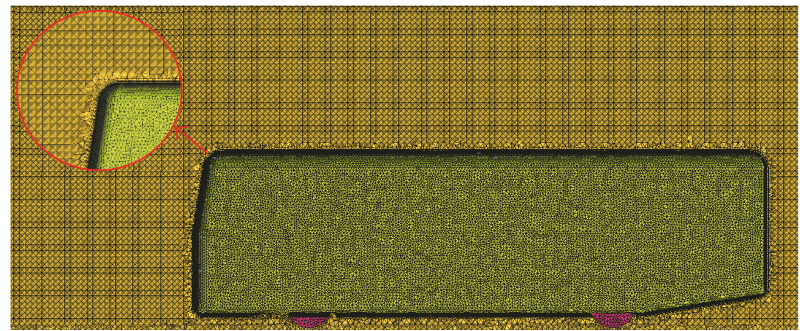

FIGURE 4: The meshes over the shell and the longitudinal symmetry plane of vehicles.

computational domain, a series of calculations are made at $35 \mathrm{~m} / \mathrm{s}$ in different blockage ratio, and the results are shown in Table 2. By comparing the aerodynamical coefficients, the blockage ratio of $0.9 \%$ is chosen, because, under this ratio, the blockage effect to the aerodynamical coefficients reduced to the minimum while ensuring a relatively smaller dimensions of the computation domain at the same time. The dimensions of computation domain are shown in Figure 3, among which, $L, W, H$ is the length, width, and height of the bus, respectively.

All meshes in the computational domain are tetrahedron elements. In order to improve the simulation quality, 6 layers of boundary meshes are established over the surface to catch more details of the viscous flow, shown as the red circle marks in Figure 4. The total height of the boundary layer meshes is set to $50 \mathrm{~mm}$. The magnitudes of $Y^{+}$shown in Figure 5 are all in the range of 10 to 300 , which indicates 


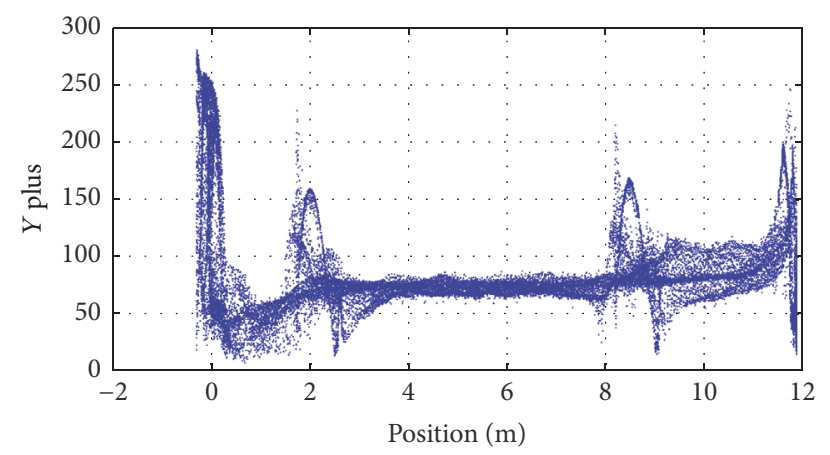

FIGURE 5: $Y^{+}$over the surface of the vehicles.

TABLE 3: Boundary conditions.

\begin{tabular}{lc}
\hline & Bus \\
\hline Inlet & Velocity inlet, $V_{\infty}=35 \mathrm{~ms}^{-1}$ \\
Outlet & Pressure outlet, $P=0 \mathrm{~Pa}$ \\
Floor & Translational moving wall, $V=35 \mathrm{~ms}^{-1}$ \\
Roof & Symmetry \\
Wall & Symmetry \\
Bus & Stationary wall \\
Leading edge cylinders & Rotational moving wall \\
\hline
\end{tabular}

the rationality of the boundary layer meshes. Another way to improve the simulation quality is to establish mesh density around the bus. The mesh density is the grey cuboid shown with its dimensions in Figure 3. After calculation by the software named ICEM, the total number of the meshes is about 2,200,000.

3.2. Boundary Conditions. The Reynolds number is calculated by (4), where $\mu$ is the viscosity coefficient which equals $1.81 \times 10^{-5} \mathrm{~Pa} \cdot \mathrm{s}$ :

$$
\operatorname{Re}=\frac{\rho V l}{\mu} .
$$

The Reynolds number of the bus is $1.6 \times 10^{6}$, which means that the flow in the computational domain is unsteady turbulence, and it is consistent to that in the experiment [1]. A pressure-based transient solver is selected in order to improve the accuracy of the calculation.

According to the calculated Reynolds number and $Y^{+}$, one of the RANS models, the realizable $K$-epsilon model, is chosen as the turbulence model with nonequilibrium wall functions. A second-order upwind scheme is used to discretize the momentum, the turbulent kinetic energy, and the turbulent dissipation rate. The boundary conditions are shown in Table 3.

3.3. Verification of Simulation Validity. The tested bus in the experiment is shown in Figure 6 [1], of which $C_{d}$ and $C_{l}$ are 0.47 and -0.24 , respectively. In this paper, an approximate simplified model is selected with some subordinate details neglected including the windows, handles, and rearview mirrors. Also, the bottom of the vehicle is simplified to a

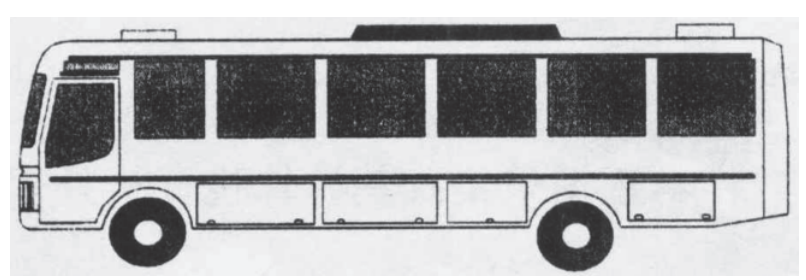

FIGURE 6: Bus model in the experiment [1].

TABLE 4: The original aerodynamic coefficients without the optimization.

\begin{tabular}{cccccc}
\hline & $C_{d}$ & $C_{s}$ & $C_{l}$ & $C_{m}$ & $C_{m l}$ \\
\hline Bus & 0.38 & -0.001 & -0.29 & -0.004 & -0.06 \\
\hline
\end{tabular}

flat surface without considering the details of the chassis structure. As a result, $C_{d}$ and $C_{l}$ of this model are 0.38 and -0.29 , respectively, which are smaller than the experimental data.

\section{Procedure and Results of the Wake Flow Optimization}

4.1. The Procedure of the Wake Flow Optimization. (1) Calculate the original aerodynamic coefficients at the velocity of $35 \mathrm{~m} / \mathrm{s}$. The results of the calculations are shown in Table 4, and they are set as the reference values of the following optimizations.

(2) Rotate the upper leading edge cylinder while the lower one keeps stationary. Then, calculate the variation of aerodynamic coefficients with the speed of the rotating cylinder as it increases from 0 . Then, compare the calculation results to that in Table 4, and find the speed at which the optimal aerodynamic performance is reached. By comparing Figures $7(\mathrm{a})$ and $7(\mathrm{~b}), 250 \mathrm{rad} / \mathrm{s}$ is selected as the optimal speed of the upper leading edge cylinder.

Then, rotate the lower leading edge cylinder while the upper one keeps stationary, and calculate the variation of aerodynamic coefficients with the velocity of the lower cylinder. The results are shown in Figure 8. By comparing Figures $8(\mathrm{a})$ and $8(\mathrm{~b}), 1300 \mathrm{rad} / \mathrm{s}$ is selected as the optimal speed of the lower leading edge cylinder.

It can be concluded from above that the global optimizing speed of the cylinders when they rotate simultaneously is in the neighborhood of $250 \mathrm{rad} / \mathrm{s}$ of upper cylinder and $1300 \mathrm{rad} / \mathrm{s}$ of lower cylinder.

(3) Calculate $C_{d}$ of the bus with both cylinders rotating simultaneously at various speed.

The speeds of the upper and lower cylinder range from $100 \mathrm{rad} / \mathrm{s}$ to $500 \mathrm{rad} / \mathrm{s}$ and $1000 \mathrm{rad} / \mathrm{s}$ to $1600 \mathrm{rad} / \mathrm{s}$, respectively, with a velocity step of $50 \mathrm{rad} / \mathrm{s}$. Then we get 143 calculation results. Accordingly, a fitting 3D plot of the speed of the cylinders versus $C_{d}$ is shown as Figure 9.

(4) Find the minimum $C_{d}$ along the fitting surface in Figure 9; the method comes from Nocedal and Wright (1999) [13]. In this situation, the minimum $C_{d}$ is 0.286 ; 




(a) Drag force coefficient

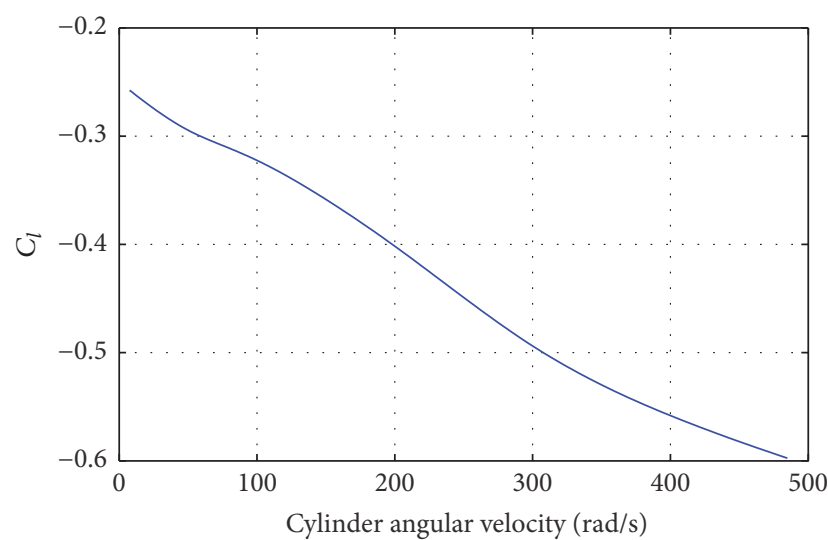

(b) Lift force coefficient

FIGURE 7: Aerodynamic coefficients with different speed of the upper rotating cylinder.

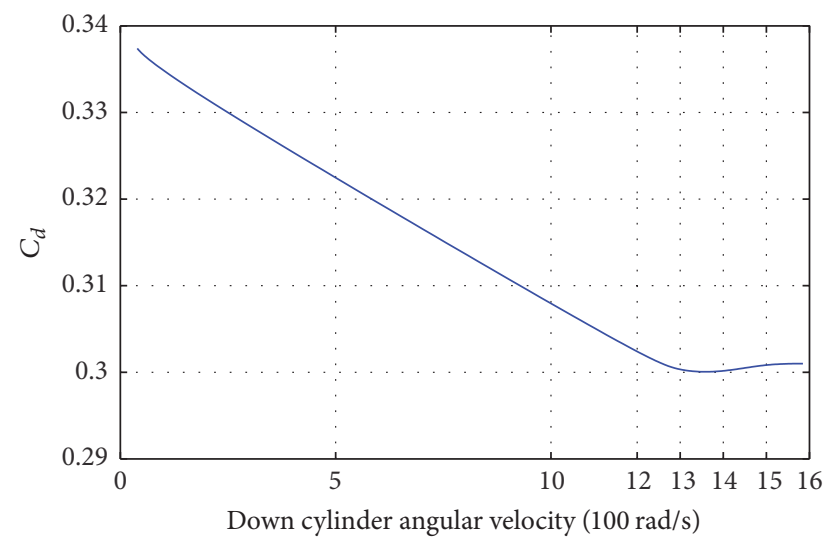

(a) Drag force coefficient



(b) Lift force coefficient

FIGURE 8: Aerodynamic coefficients with different speed of the lower rotating cylinder.

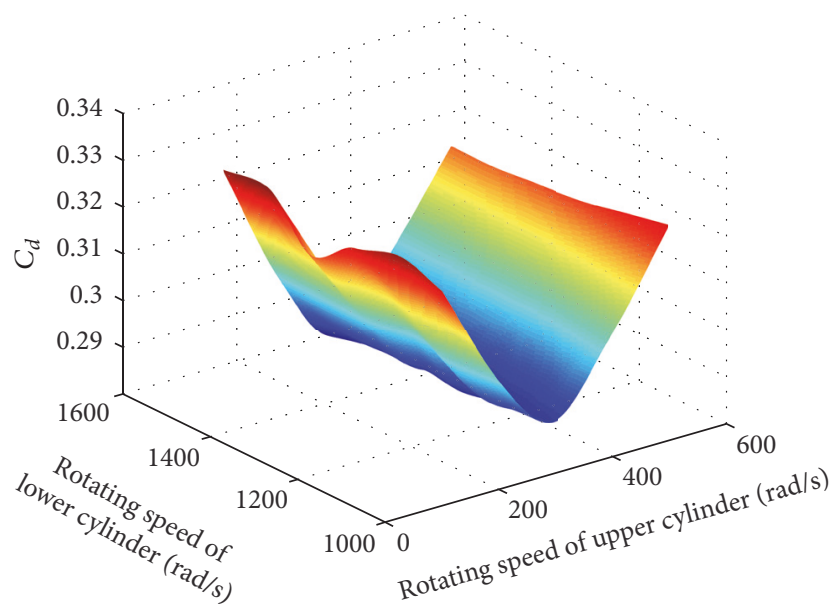

Figure 9: $C_{d}$ in different speeds of cylinders.

the corresponding speeds of upper and lower cylinder are $293 \mathrm{rad} / \mathrm{s} 1241 \mathrm{rad} / \mathrm{s}$, respectively.
(5) Calculate $C_{d}$ of the bus when the speeds of the upper and lower cylinders are $293 \mathrm{rad} / \mathrm{s}$ and $1241 \mathrm{rad} / \mathrm{s}$, respectively, through simulation on the platform of ANSYS/Fluent. The simulation result of $C_{d}$ is 0.288 and the error is $0.70 \%$ compared to the mathematical result in step (4). The validity of the fitting method in step (3) is verified.

(6) $C_{l}$ of the bus at the speeds of the upper and lower cylinders of $293 \mathrm{rad} / \mathrm{s}$ and $1241 \mathrm{rad} / \mathrm{s}$ is -0.33 , and it is decreased by $13.8 \%$ compared to $C_{l}$ in Table 4 , which helps to increase the ground adhesive force of the bus.

In conclusion, the most effective optimization occurs when the upper cylinder rotates at $293 \mathrm{rad} / \mathrm{s}$ and the lower cylinder rotates at $1241 \mathrm{rad} / \mathrm{s}$. The aerodynamic coefficients after optimization are compared to the data in Table 4, which is shown in Table $5 . C_{d}$ is reduced by $24.7 \%$ and $C_{l}$ by $13.8 \%$, which verifies the validity of this optimization.

4.2. Variability in the Flow Characteristics. The vorticity contours at the longitudinal symmetric plane of the bus are shown in Figure 10. By comparing Figures 10(a)-10(b), the velocity of the flow from the upper and lower surface decelerates obviously, and the area of high vorticity region 
TABLE 5: The comparisons of aerodynamic coefficients.

\begin{tabular}{lcc}
\hline & $C_{d}$ & $C_{l}$ \\
\hline Original data & 0.38 & -0.291 \\
Optimized data & 0.286 & -0.33 \\
Reduction ratio & $-24.7 \%$ & $13.8 \%$ \\
\hline
\end{tabular}

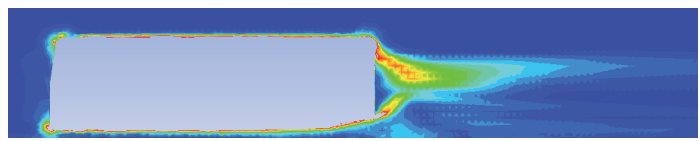

(a) The vorticity contour without optimization

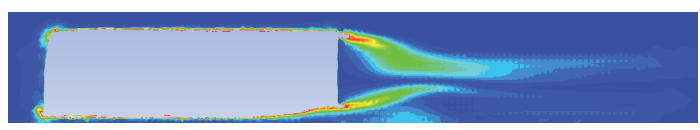

(b) The vorticity contour after the optimization

Figure 10: The vorticity contours at the longitudinal symmetry plane.

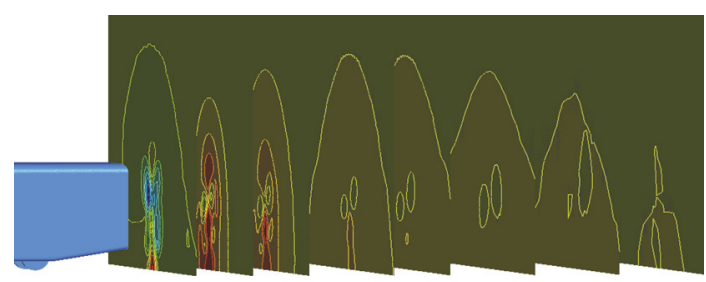

(a) The pressure contours without optimization



(b) The pressure contours after the optimization

FIGURE 11: The pressure contours on the planes every 2 meters behind tail.

decreases. At the same time, the dimensions of the wake vortices increase when the meeting point of flow from the upper and lower surface moves further from the tail, which increases the pressure of tail and decreases $C_{d}$.

The pressure contours on the planes every 2 meters behind the tail are shown in Figure 11. There are four lowpressure regions on the first plane behind the original bus, which means there are four vortices in this region. Because of the gravity, the lower pair of vortices disappears earlier while the upper pair of vortices trails further. However, after the optimization, the pressure distribution on the first plane behind the tail is better distributed, and the length of the tailing vortices is shortened obviously, which can improve the crosswind stability of the bus.
4.3. Sensitivity of the Optimal Speeds of Cylinders to the Bus Velocity. According to the procedure in Section 4.1, the optimal speeds of the cylinders are calculated at the bus velocity of $25 \mathrm{~m} / \mathrm{s}$ to $35 \mathrm{~m} / \mathrm{s}$. The results are shown in Figure 12. Because $C_{d}$ is small at low velocities, the air drag accounts for a relatively minor portion of the vehicle driving resistance. Consequently, the optimizing effect of this method is not obvious at low velocities, so the situation of the bus velocity less than $25 \mathrm{~m} / \mathrm{s}$ is not discussed in this research. Moreover, the upper limit of the vehicle velocity in highway in China is $35 \mathrm{~m} / \mathrm{s}$, and the limit of the bus is $30 \mathrm{~m} / \mathrm{s}$. As a result, the maximum velocity in this sensitivity research is set to $35 \mathrm{~m} / \mathrm{s}$ and the situation in higher velocity is not discussed in this research.

The comparisons of $C_{d}$ between the original data and optimized data are shown in Figure 13. It can be concluded from Figure 13 that the higher the velocity of the bus is, the better the optimization effect will be. The most obvious drag reduction is in the velocity of $35 \mathrm{~m} / \mathrm{s}$, and the ratio of drag reduction is $24.7 \%$.

4.4. System-Level Energy Study. In order to explore the practicality of this method, this chapter tries to evaluate the method from the aspect of the vehicle driving energy consumption and verify the improvement of the vehicle fuel economy at high velocity.

In this chapter, the fuel economy of a bus with and without the optimization method under a driving condition of constant velocity of $35 \mathrm{~m} / \mathrm{s}$ is calculated.

4.4.1. Power Required to Accelerate Cylinders to Target Speed. The calculation method of the power required to rotate cylinders to target speed is explained as follows.

(1) Calculate the inertia moment of cylinders by the following formula:

$$
J=\frac{1}{2} m r^{2}
$$

(see [14]) where $m$ is the mass of cylinder and $r$ is the radius of cylinder.

In order to reduce the mass and maintain the rigidity of cylinder, the material of cylinder is designed to aluminum, and the structure of cylinder is designed to an aluminum skin in $2 \mathrm{~mm}$ and a honeycomb core inside it. The density of the cylinder is $22 \mathrm{~kg} / \mathrm{m}^{3}$ [15].

Mass of upper cylinder is

$$
m_{\mathrm{up}}=\rho \pi r_{\mathrm{up}}^{2} L_{\mathrm{up}}=21.5 \mathrm{~kg} .
$$

Mass of lower cylinder is

$$
m_{\text {down }}=\rho \pi r_{\text {down }}^{2} L_{\text {down }}=2.9 \mathrm{~kg},
$$

where $r_{\text {up }}$ and $r_{\text {down }}$ are the radius of the upper and lower cylinder; $L_{\text {up }}$ and $L_{\text {down }}$ are the length of the upper and lower cylinder. $r_{\text {up }}, r_{\text {down }}, L_{\text {up }}, L_{\text {down }}$ are shown in Table 1.

Moment of inertia of upper cylinder is

$$
J_{\text {up }}=\frac{1}{2} m_{\text {up }} r_{\text {up }}^{2}=0.968 \mathrm{~kg} \cdot \mathrm{m}^{2} .
$$




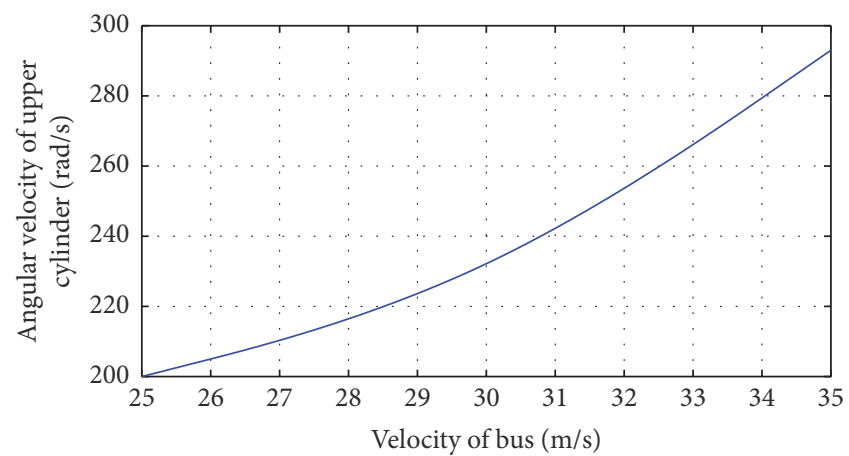

(a) The optimal speeds of upper cylinder

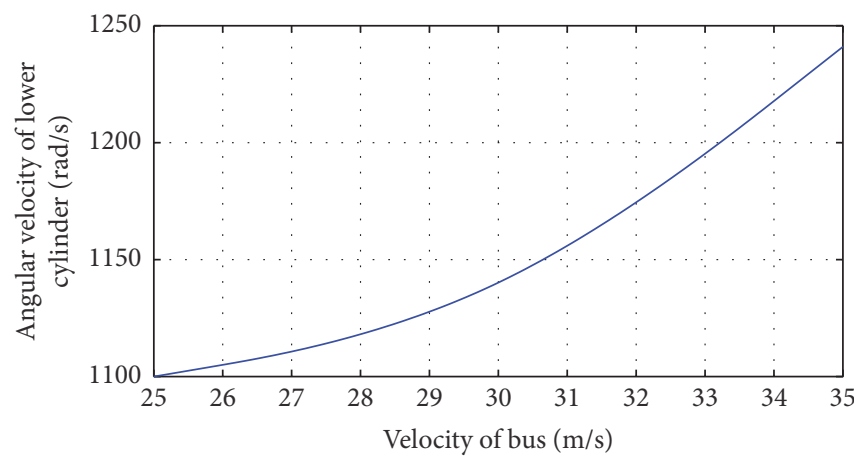

(b) The optimal speeds of lower cylinder

FIGURE 12: The optimal speeds of cylinders at different bus velocities.

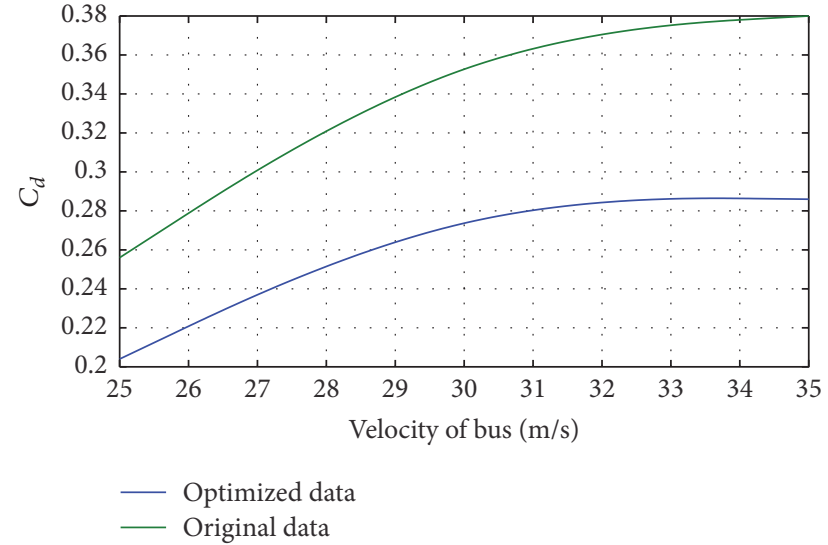

Figure 13: The comparisons of $C_{d}$ at different bus velocities.

Moment of inertia of lower cylinder is

$$
J_{\text {down }}=\frac{1}{2} m_{\text {down }} r_{\text {down }}^{2}=0.015 \mathrm{~kg} \cdot \mathrm{m}^{2} .
$$

(2) Calculate the angular acceleration of cylinders when the time of driving cylinders from 0 to the target speed is $60 \mathrm{~s}$.

Angular acceleration of upper cylinders is

$$
\beta_{\text {up }}=\frac{\theta_{\text {up }}}{t}=4.9 \mathrm{rad} / \mathrm{s}^{2} .
$$

Angular acceleration of lower cylinders is

$$
\beta_{\text {down }}=\frac{\theta_{\text {down }}}{t}=20.7 \mathrm{rad} / \mathrm{s}^{2} .
$$

(3) Calculate torque of cylinders.

Torque of upper cylinders is

$$
T_{\text {up }}=J_{\text {up }} \beta_{\text {up }}=4.7 \mathrm{~N} \cdot \mathrm{m} \text {. }
$$

Torque of lower cylinders (see [16]) is

$$
T_{\text {down }}=J_{\text {down }} \beta_{\text {down }}=0.3 \mathrm{~N} \cdot \mathrm{m} .
$$

(4) Calculate the power of cylinders.
Power of upper cylinder is

$$
P_{\text {up }}=\frac{\pi}{30} \times T_{\text {up }} \times n_{\text {up }} .
$$

Power of lower cylinder is

$$
P_{\text {down }}=\frac{\pi}{30} \times T_{\text {down }} \times n_{\text {down }},
$$

where $n_{\text {up }}$ and $n_{\text {down }}$ are the numbers of revolutions in a minute of upper and lower cylinder:

$$
\begin{aligned}
n_{\text {up }} & =2799 \mathrm{rmp}, \\
n_{\text {down }} & =11857 \mathrm{rmp} .
\end{aligned}
$$

After the calculation,

$$
\begin{aligned}
P_{\text {up }} & =1.377 \mathrm{~kW}, \\
P_{\text {down }} & =0.372 \mathrm{~kW} .
\end{aligned}
$$

Power of the rotating cylinders is

$$
P=P_{\text {up }}+P_{\text {down }}=1.749 \mathrm{~kW} .
$$

Because the power required to rotate cylinders to speed is only $1.749 \mathrm{~kW}$ and the working time is only $60 \mathrm{~s}$, the influences of this power to the fuel consumption can be ignored.

4.4.2. Power Required to Rotate the Cylinders at a Constant Speed. Rotating the cylinders requires extra power from the vehicle, which will increase the fuel consumption. On the other hand, the rotating cylinders significantly decrease the air drag of the vehicle, which in contrast decreases the fuel consumption. After all, to evaluate the fuel economy optimization of this method, we should first calculate the power required to rotate the cylinders. The calculation method is as follows.

(1) Calculate the skin friction coefficients of cylinders using the facet-average method on the platform of ANSYS/Fluent. 
Skin friction coefficient of upper cylinder is

$$
c_{\text {up }}=0.013 \text {. }
$$

Skin friction coefficient of lower cylinder is

$$
c_{\text {down }}=0.045 \text {. }
$$

(2) Surface shear stress of cylinders is calculated. Surface shear stress of upper cylinder is

$$
\tau_{\text {up }}=c_{\text {up }} \times q_{\infty} \text {. }
$$

Surface shear stress of lower cylinder is

$$
\tau_{\text {down }}=c_{\text {down }} \times q_{\infty} \text {, }
$$

where $q_{\infty}$ is freestream dynamic pressure:

$$
q_{\infty}=\frac{1}{2} \rho_{\infty} V_{\infty}^{2}
$$

where $\rho_{\infty}$ is the density of air, $\rho_{\infty}=1.225 \mathrm{~kg} / \mathrm{m}^{3} ; V_{\infty}$ is the velocity of freestream, $V_{\infty}=30 \mathrm{~m} / \mathrm{s}$.

After the calculation,

$$
\begin{aligned}
\tau_{\text {up }} & =7.166, \\
\tau_{\text {down }} & =24.806 .
\end{aligned}
$$

(3) Calculate the skin friction.

The skin friction of upper cylinder is

$$
F_{\text {up }}=\tau_{\text {up }} \times S_{\text {up }}
$$

The skin friction of lower cylinder is

$$
F_{\text {down }}=\tau_{\text {down }} \times S_{\text {down }}
$$

where $S_{\text {up }}$ and $S_{\text {down }}$ are the contact areas between the cylinders and air:

$$
\begin{aligned}
S_{\text {up }} & =2 \pi r_{\text {up }} L_{\text {up }} \frac{\alpha}{360}, \\
S_{\text {down }} & =2 \pi r_{\text {down }} L_{\text {down }} \frac{\beta}{360},
\end{aligned}
$$

where $r_{\text {up }}$ and $r_{\text {down }}$ are the radius of the upper and lower cylinder; $L_{\text {up }}$ and $L_{\text {down }}$ are the length of the upper and lower cylinder. $r_{\text {up }}, r_{\text {down }}, L_{\text {up }}, L_{\text {down }}, \alpha, \beta$ are shown in Table 1.

After the calculation,

$$
\begin{aligned}
S_{\text {up }} & =0.895 \mathrm{~m}^{2}, \\
S_{\text {down }} & =0.325 \mathrm{~m}^{2} .
\end{aligned}
$$

Then, the skin friction can be calculated:

$$
\begin{aligned}
F_{\text {up }} & =6.416 \mathrm{~N}, \\
F_{\text {down }} & =8.062 \mathrm{~N} .
\end{aligned}
$$

(4) Calculate the torque of cylinders.
Torque of upper cylinder is

$$
T_{\text {up }}=F_{\text {up }} \times r_{\text {up }}=1.925 \mathrm{~N} \cdot \mathrm{m} \text {. }
$$

Torque of lower cylinder is

$$
T_{\text {down }}=F_{\text {down }} \times r_{\text {down }}=0.806 \mathrm{~N} \cdot \mathrm{m} .
$$

(5) Calculate the power of cylinders.

Power of upper cylinder is

$$
P_{\text {up }}=\frac{\pi}{30} \times T_{\text {up }} \times n_{\text {up }} .
$$

Power of lower cylinder is

$$
P_{\text {down }}=\frac{\pi}{30} \times T_{\text {down }} \times n_{\text {down }}
$$

where $n_{\text {up }}$ and $n_{\text {down }}$ are the numbers of revolutions in a minute of upper and lower cylinder:

$$
\begin{aligned}
n_{\text {up }} & =2799 \mathrm{rmp}, \\
n_{\text {down }} & =11857 \mathrm{rmp} .
\end{aligned}
$$

After the calculation,

$$
\begin{aligned}
P_{\text {up }} & =0.564 \mathrm{~kW}, \\
P_{\text {down }} & =1.000 \mathrm{~kW} .
\end{aligned}
$$

Power of the rotating cylinders is

$$
P=P_{\text {up }}+P_{\text {down }}=1.564 \mathrm{~kW} \text {. }
$$

4.4.3. Verification of the Optimization to the Vehicle Fuel Economy. To verify the optimization effect of this method from the aspect of the vehicle fuel economy, a vehicle model is established on the platform of AVL/Cruise which is a system-level vehicle performance simulation software that can calculate the fuel economy and power performance and so forth. The model is shown in Figure 14.

In this model, the appearance-related vehicle parameters come from Table 6, and the parameters of the powertrain come from the reference bus model in Cruise. The main specifications of the model are shown in Table 6.

A simulation is run at a constant bus velocity of $35 \mathrm{~m} / \mathrm{s}$ based on the model above. Before optimization, the fuel consumption is $31.34 \mathrm{~L} / 100 \mathrm{~km}$, while it is $30.38 \mathrm{~L} / 100 \mathrm{~km}$ after optimization. The fuel economy is improved by $3.1 \%$. The results verify that this optimization method can effectively improve the bus fuel economy.

\section{The Application and Effect of This Optimization Method under Different Conditions}

The effects of this optimization under such conditions as driving in crosswind, overtaking maneuvers, and driving in platoon are discussed below. In the discussions, the velocity of the bus is $35 \mathrm{~m} / \mathrm{s}$ and the speed of upper and lower cylinder are $293 \mathrm{rad} / \mathrm{s}$ and $1241 \mathrm{rad} / \mathrm{s}$. 




Figure 14: Bus model in AVL/Cruise.

TABLE 6: The main specifications of the bus model.

\begin{tabular}{|c|c|c|c|}
\hline \multirow{2}{*}{ Assembly } & \multirow{2}{*}{ Unit } & \multicolumn{2}{|c|}{ Value } \\
\hline & & Original & Optimized \\
\hline \multicolumn{4}{|l|}{ Vehicle } \\
\hline$C_{d}$ & - & 0.38 & 0.286 \\
\hline Extra power required to rotate the cylinders & $\mathrm{kW}$ & 0 & 1.564 \\
\hline Wheel base & $\mathrm{m}$ & \multicolumn{2}{|c|}{6.4} \\
\hline Length/width/height & $\mathrm{m}$ & \multicolumn{2}{|c|}{$12 / 2.5 / 3.4$} \\
\hline Kerb mass & $\mathrm{kg}$ & \multicolumn{2}{|c|}{11500} \\
\hline Frontal area & $\mathrm{m}^{2}$ & \multicolumn{2}{|c|}{9.3} \\
\hline \multicolumn{4}{|l|}{ Engine } \\
\hline Type & - & \multicolumn{2}{|c|}{$\begin{array}{l}\text { Diesel engine with } \\
\text { turbocharger }\end{array}$} \\
\hline Displacement & $\mathrm{L}$ & \multicolumn{2}{|c|}{8.06} \\
\hline Max. power & $\mathrm{kW} / \mathrm{rpm}$ & \multicolumn{2}{|c|}{ 152kW/@2300 } \\
\hline \multicolumn{4}{|l|}{ Transmission } \\
\hline Type & - & \multicolumn{2}{|c|}{$5 \mathrm{AMT}$} \\
\hline \multicolumn{4}{|l|}{ Tire } \\
\hline Type & - & \multicolumn{2}{|c|}{ 275/70 R26 } \\
\hline
\end{tabular}




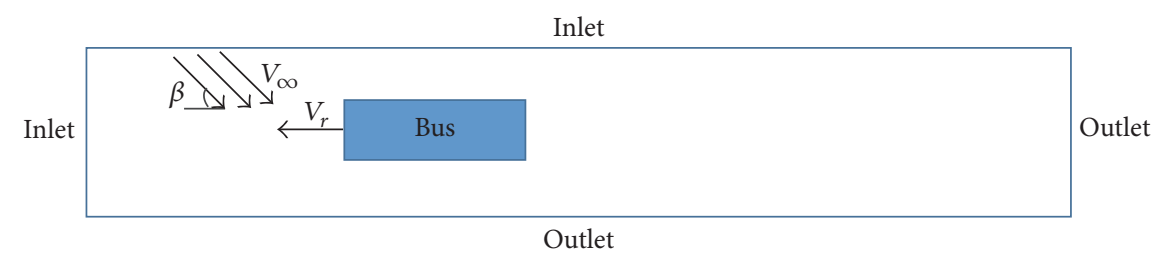

FIgURE 15: The computational domain and the model in crosswind.

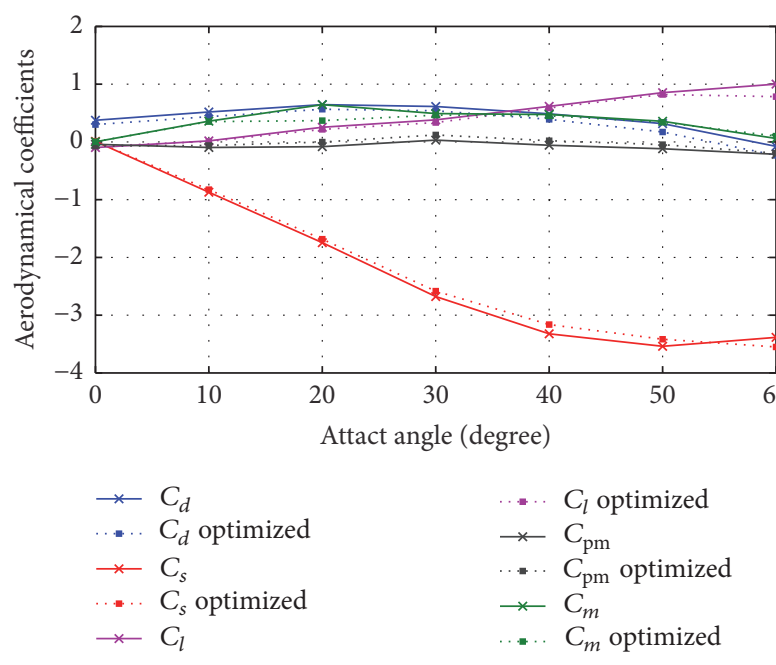

FIGURE 16: The aerodynamic coefficients in different attack angle.

5.1. The Optimization Results under Crosswind. The computational domain and the bus model in crosswind driving are shown in Figure 15. The velocity of crosswind $V_{\infty}$ is set to $5 \mathrm{~m} / \mathrm{s}$, the velocity of bus $V_{r}$ is set to $35 \mathrm{~m} / \mathrm{s}$, and the attack angle $\beta$ is between 0 and $60^{\circ}$.

In order to decrease the blockage effect of the computational domain and increase the airflow uniformity, the inlets and outlets are set as shown in Figure 15. The velocity of inlets is $5 \mathrm{~m} / \mathrm{s}$; the direction is changed with the attack angle $\beta$. The pressure of outlets is 0 . The bus body is set to a moving wall whose velocity is $35 \mathrm{~m} / \mathrm{s}$ and the direction is shown in Figure 15. The floor is set to a stationary wall. The surfaces of upper and lower cylinders are set to a rotating wall at $-293 \mathrm{rad} / \mathrm{s}$ and $1241 \mathrm{rad} / \mathrm{s}$. The dimensions and the mesh design of the computational domain are the same as that in Section 3 .

The aerodynamic coefficients under different attack angles are shown in Figure 16. This optimization works well in crosswind driving when the attack angle of crosswind ranges from 0 to $60^{\circ} . C_{d}, C_{l}, C_{\mathrm{pm}}$ decrease with a narrow range after the optimization. Moreover, $C_{s}$ and $C_{m}$, which are given more attention in crosswind, are optimized effectively. For $C_{m}$, the most effective optimization takes place when the attack angle is $20^{\circ}$. The original $C_{m}$ is 0.645 , and the optimized $C_{m}$ is 0.369 . The ratio of the reduction is $42.8 \%$. Similarly, for $C_{s}$, the most effective optimization takes place when the attack angle is $40^{\circ}$. The original $C_{s}$ is 3.323 , and the optimized $C_{s}$ is 3.163 . The ratio of the decreasing is $4.8 \%$.
The maximum, minimum, and mean values of the aerodynamical coefficients in crosswind conditions are shown in Table 7. The optimizing rates of these values are computed and shown in the right line in Table 7 . The optimizing rates of $C_{d}, C_{s}, C_{l}$, and $C_{m}$ are all negative, and that of $C_{\mathrm{pm}}$ is positive, which means that this method can effectively optimize all the aerodynamical coefficients in crosswind condition.

The flow fields in crosswind driving with an attack angle of $60^{\circ}$ are shown in Figure 17. Before the optimization, there are three clear vortices on the leeward side shown in the red circle, which affects the bus stability under crosswind and increases $C_{s}$. After the optimization, there is no clear vortex, and the stability increases.

5.2. The Optimization Results during Overtaking Maneuvers. The physical model of overtaking maneuvers in which a car overtakes a bus at the relative velocity of $5 \mathrm{~m} / \mathrm{s}$ is shown in Figure 18. Comparisons are made between aerodynamic coefficients of both vehicles before and after the optimization of the wake flow of the bus. The overtaking maneuvers begin at the position where the car is $2 L_{\text {car }}$ behind the bus, which is shown in Figure 18. During the overtaking maneuvers, the car totally moves $8 L_{\text {car }}$.

A MIRA model without wheel is chosen as the car model, which is shown in Figure 19, and the bus model is shown in Figure 1. The dimensions of the car model [10] are shown in Table 8.

The computational domain of the overtaking simulation is shown in Figure 20. The overall domain is composed of two subdomains: SD-bus which contains the bus and remains fixed during the simulation and SD-car which contains car and moves with it at the same velocity. The movement of car is realized by adopting the sliding mesh method. The size of the computational domain is $7 \mathrm{~W}$ outer side of the models and $4 \mathrm{~L}$ upstream and $7 L$ downstream of the models. The total height of the computational domain is $8.5 H(L, W, H$ are the length, width, and height of models, resp.).

The meshes in the computational domain are all tetrahedral structures generated on the platform of ICEM, and the meshes over the shell and the longitudinal symmetry plane of car are shown in Figure 21. In order to improve the simulation quality, 6 layers of boundary meshes are established along the surface to catch more details of the viscous flow, as the figure in the red circle shows. The total height of the boundary layer meshes is set to $50 \mathrm{~mm}$. The magnitudes of $Y^{+}$at the end of the simulation are all in range of 10 to 300 , which indicates the rationality of the design of the boundary layer meshes. Another way to improve the simulation quality is to establish mesh densities around the vehicles. The mesh densities are 
TABLE 7: The maximum and minimum of aerodynamical coefficients.

\begin{tabular}{|c|c|c|c|c|c|}
\hline & & Attack angle (degree) & Unoptimized & Optimized & Optimizing rate (\%) \\
\hline \multirow{3}{*}{$C_{d}$} & Maximum & 20 & 0.646 & 0.566 & -12.4 \\
\hline & Minimum & 60 & -0.077 & -0.233 & -202.6 \\
\hline & Mean value & - & 0.411 & 0.310 & -24.6 \\
\hline \multirow{3}{*}{$C_{s}$} & Maximum & 0 & 0.009 & 0.003 & -66.7 \\
\hline & Minimum & 60 & -3.55 & -3.384 & -4.7 \\
\hline & Mean value & - & -2.218 & -2.173 & -2.0 \\
\hline \multirow{3}{*}{$C_{l}$} & Maximum & 60 & 3.003 & 2.352 & -21.7 \\
\hline & Minimum & 0 & -0.234 & -0.291 & -24.3 \\
\hline & Mean value & - & 1.305 & 1.139 & -12.7 \\
\hline \multirow{3}{*}{$C_{\mathrm{pm}}$} & Maximum & 30 & 0.031 & 0.121 & +290.3 \\
\hline & Minimum & 60 & -0.214 & -0.195 & +8.9 \\
\hline & Mean value & - & -0.087 & -0.029 & +66.6 \\
\hline \multirow{3}{*}{$C_{m}$} & Maximum & 20 & 0.645 & 0.369 & -42.8 \\
\hline & Minimum & 0 & 0.002 & 0.001 & -50 \\
\hline & Mean value & - & 0.341 & 0.297 & -12.9 \\
\hline
\end{tabular}

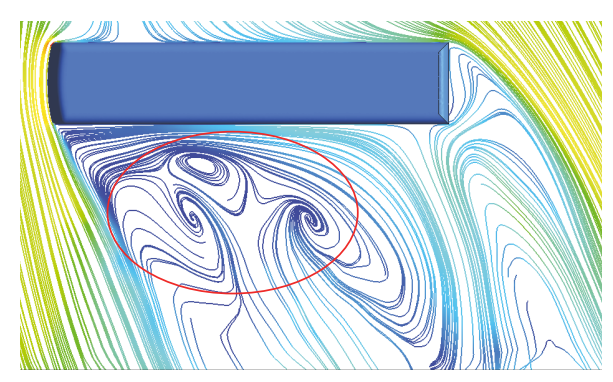

(a) Without optimization

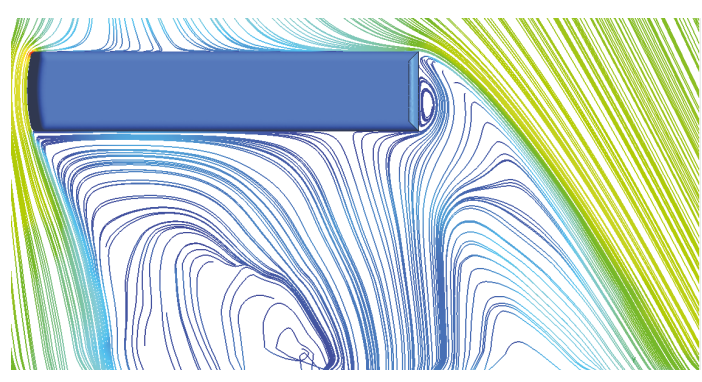

(b) Optimized

Figure 17: The flow fields in $60^{\circ}$ crosswind.

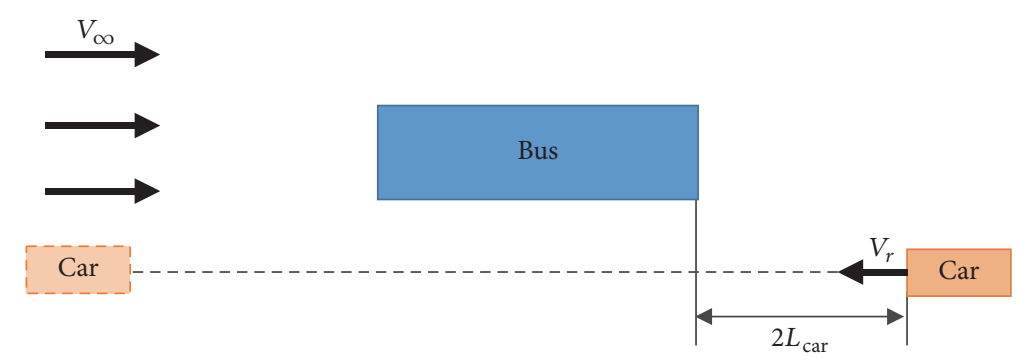

Figure 18: The physical model of overtaking maneuvers.

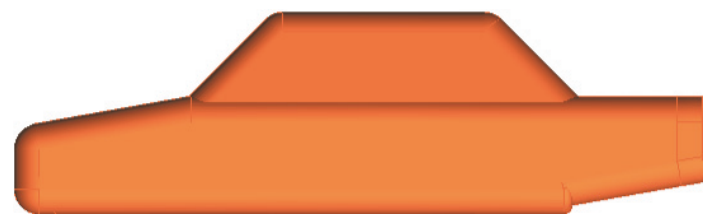

FIGURE 19: Car model.

shown as the grey cuboid in Figure 20. Their dimensions are labeled. After calculation on the platform of ICEM, the total number of the meshes is about 5,800,000. The boundary conditions are shown in Table 9.

The variations of aerodynamic coefficients of both vehicles with the position of car are shown in Figure 22. All aerodynamic coefficients of the bus are optimized during the whole maneuvers. However, the optimizing effects of aerodynamic coefficients of car are divided by Position 3.6 at which the tail of car is parallel to the nose of the bus. Before Position 3.6, this optimization works well. The wake flow of the bus influences the outer flow fields of car a lot during this stage, so optimizing the wake flow of the bus is good for the outer flow fields of car. After Position 3.6, the wake flow of the 


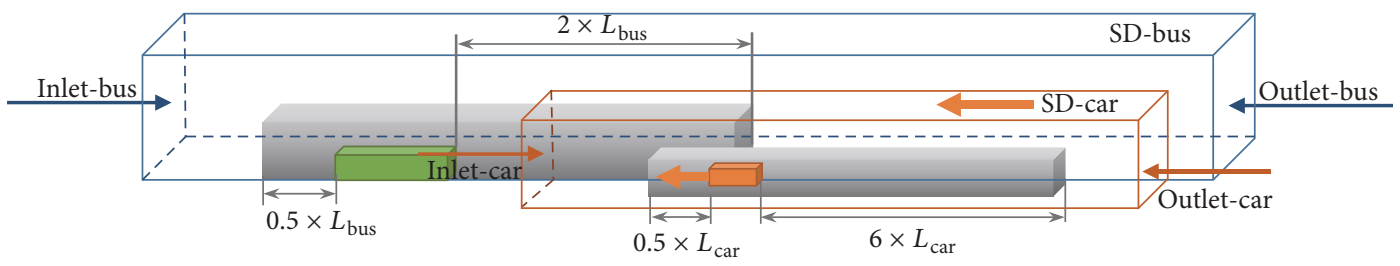

FIGURE 20: The computational domain of the overtaking simulation.

TABLE 8: Dimensions of car.

\begin{tabular}{lccccc}
\hline Length $(\mathrm{m})$ & Width $(\mathrm{m})$ & Height $(\mathrm{m})$ & Frontal area $\left(\mathrm{m}^{2}\right)$ & Side area $\left(\mathrm{m}^{2}\right)$ & Wheel base $(\mathrm{m})$ \\
\hline 3.541 & 1.381 & 1.208 & 1.98 & 5.07 & 2.159 \\
\hline
\end{tabular}

TABLE 9: Boundary condition.

\begin{tabular}{lcc}
\hline & Bus & Car \\
\hline Inlet & Velocity inlet, $V_{\infty}=35 \mathrm{~ms}^{-1}$ & Velocity inlet, $V_{\infty}=35 \mathrm{~ms}^{-1}$ \\
Outlet & Pressure outlet, $P=101325 \mathrm{~Pa}$ & Pressure outlet, $P=101325 \mathrm{~Pa}$ \\
Floor & Stationary wall & Moving wall, $V_{r}=5 \mathrm{~ms}^{-1}$ \\
Roof & Symmetry & Symmetry \\
Body & Stationary wall & Moving wall, $V_{r}=-5 \mathrm{~ms}^{-1}$ \\
Upper cylinder & Rotating wall, $V=-293 \mathrm{rad} / \mathrm{s}$ & - \\
Lower cylinder & Rotating wall, $V=1241 \mathrm{rad} / \mathrm{s}$ & - \\
Adjacent surface & Interface & Interface \\
Outside surface & Symmetry & Symmetry \\
\hline
\end{tabular}

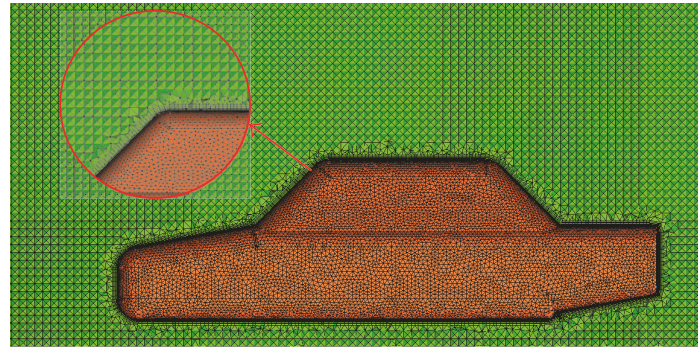

FIGURE 21: The meshes over the shell and the longitudinal symmetry plane of car.

bus does not influence the outer fields of car anymore, so the outer flow field of car cannot be optimized by optimizing the wake flow of the bus during this stage.

The reason why $C_{m}$ is so different for the bus at Position 0 is explained as follows.

Before the optimization, along with the movements of the car, the low-velocity flow before the car decreases the velocity of the flow on the inner rear side of the bus. As a result, the pressure of the inner rear side of the bus increases and $C_{m}$ of the bus increases.

After the optimization, the leading cylinders rotate in high speed. Because the height of the car is lower than that of the bus, the rotation of the lower cylinder is the main cause of the influences on the flow fields between the two vehicles. On the one hand, the lower rotating cylinder increases the velocity of the flow before the car, which decreases the area of the high pressure before the car and decreases the pressure on the inner rear side of the bus. On the other hand, the lower rotating cylinder accelerates the flow on the inner front of the car, which increases the area of the low pressure on the inner front of car. Because of the two reasons, $C_{m}$ of the bus obvious decreases.

As a result, $C_{m}$ of the bus is so different at Position 0 before and after the optimization.

The pressure fields at Position 0 are shown in Figure 23.

In order to testify that the reason that causes the difference of $C_{m}$ at Position 0 is the rotation of the lower cylinder, a series of simulations in different lower cylinder speeds are conducted. The results are shown in Figure 24. It can be seen from Figure 24 that the lower the speed, the less the differences, which testifies the correctness of the reason.

The maximum, minimum, and mean values of the vehicle aerodynamical coefficients during the overtaking maneuvers are shown in Tables 10 and 11.

According to the optimizing rate, this method can effectively optimize all the bus aerodynamical coefficients during the overtaking maneuvers.

For the car aerodynamical coefficients, this method can effectively optimize $C_{d}, C_{s}, C_{l}$ of car, while the optimizing effects of $C_{\mathrm{pm}}$ and $C_{m}$ are not satisfactory. The optimizing rates of the minimum and mean value are negative when the positive rates are needed. Similarly, the optimizing rate of the maximum and mean value is positive when the negative rates are needed. In general, the optimizing effects on the car aerodynamical coefficients can be acceptable. 


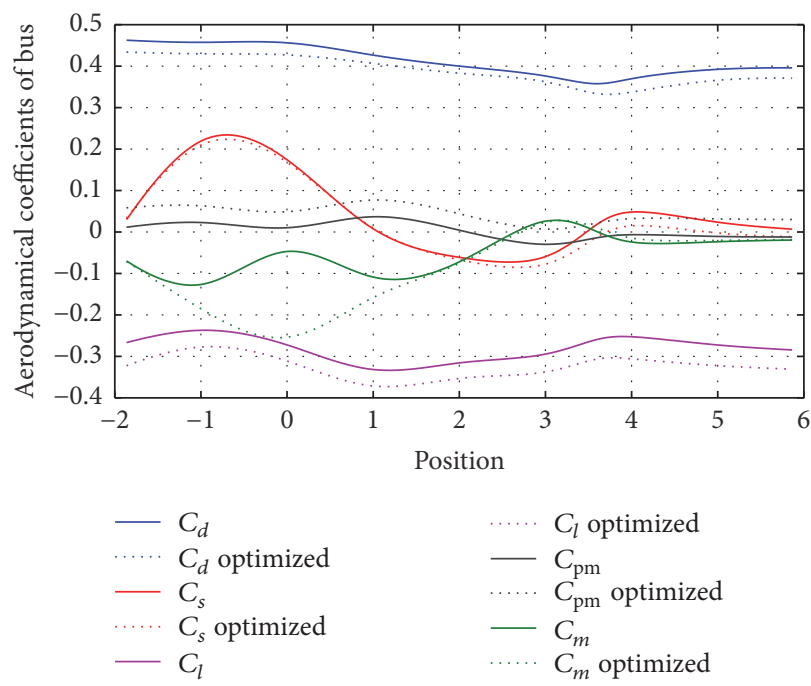

(a) The aerodynamic coefficients history of bus

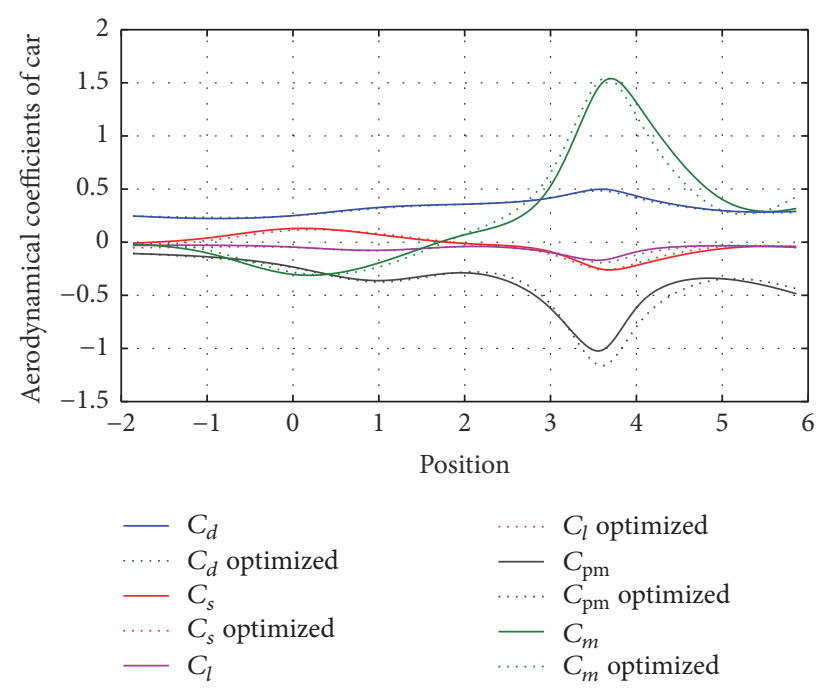

(b) The aerodynamic coefficients history of car

FIGURE 22: The aerodynamic coefficients history during the overtaking maneuvers.

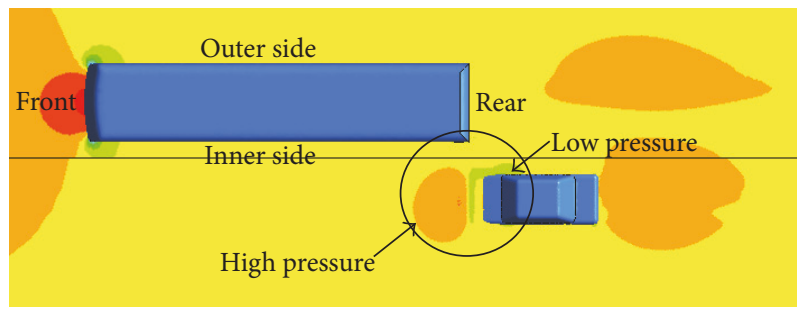

(a) The pressure field before the optimization

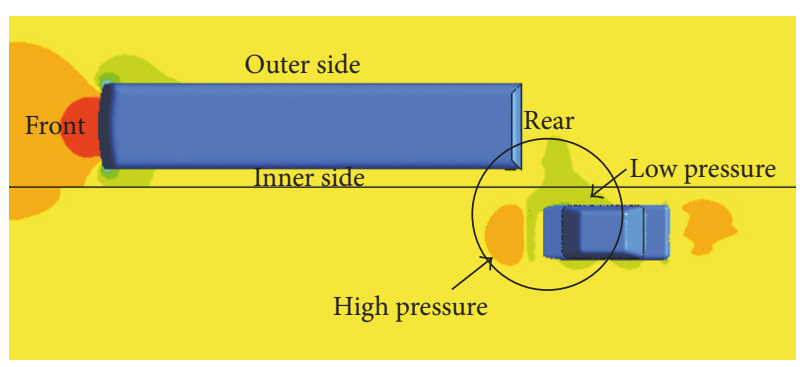

(b) The pressure field after the optimization

Figure 23: The pressure field in Position 0.

The vorticity contours in Position -1 during the overtaking maneuvers are shown in Figure 25. The high vorticity region of both vehicles decreases obviously after the optimization. The flow fields around the two vehicles are optimized at the same time.

5.3. The Optimization Results under Platoon Driving. The physical model of platoon driving is shown in Figure 26. The two identical buses move in platoon at $30 \mathrm{~m} / \mathrm{s}$ in the same path. The length of the bus is labeled as $L$, and the distance between the two buses is set to $0.5 \mathrm{~L}$ (shown in Figure 26). The leading edge rotating cylinders are installed to the tail of the front bus, the boundary conditions are shown in Table 12,

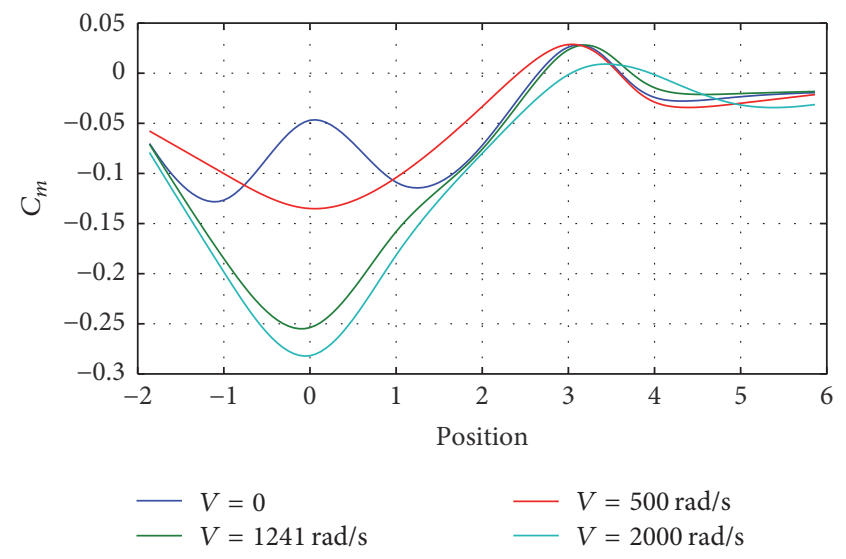

FIGURE 24: $C_{m}$ of bus in different lower cylinder speeds.

and the influences that the wake flow of the front bus exerts on the back bus are discussed. The aerodynamic coefficients of both buses are shown in Table 13. $C_{d}, C_{l}$, and $C_{\mathrm{pm}}$ of the front bus are optimized significantly, while those of the back bus are slightly optimized. As a result, optimizing the wake flow of the front bus is good for the outer flow fields of the back bus.

The streamline on the longitudinal symmetry plane in platoon driving is shown in Figure 27. The wake vortices of the front bus are smoothed obviously after the optimization. Meanwhile, the pressure in front of the back bus decreases and the wake vortices decelerates. The flow fields of both buses are optimized at the same time.

\section{Conclusion}

In this paper, the leading edge rotating cylinder is used to optimize the wake flow of a bus. It is installed at the upper and lower edge of the bus tail. The rotating directions of both 
TABLE 10: The maximum, minimum, and mean values of the bus aerodynamical coefficients.

\begin{tabular}{|c|c|c|c|c|c|}
\hline & & Position & Unoptimized & Optimized & Optimizing rate (\%) \\
\hline \multirow{3}{*}{$C_{d}$} & Maximum & 0 & 0.465 & 0.432 & -7.1 \\
\hline & Minimum & 3.6 & 0.348 & 0.325 & -6.6 \\
\hline & Mean value & - & 0.410 & 0.386 & -5.8 \\
\hline \multirow{3}{*}{$C_{s}$} & Maximum & -1 & 0.282 & 0.268 & -5.0 \\
\hline & Minimum & -3 & -0.086 & -0.102 & -18.6 \\
\hline & Mean value & - & 0.041 & 0.027 & -34.1 \\
\hline \multirow{3}{*}{$C_{l}$} & Maximum & -1 & -0.221 & -0.257 & -16.3 \\
\hline & Minimum & 1 & -0.354 & -0.395 & -11.6 \\
\hline & Mean value & - & -0.279 & -0.324 & -16.1 \\
\hline \multirow{3}{*}{$C_{\mathrm{pm}}$} & Maximum & 1 & 0.056 & 0.097 & +73.2 \\
\hline & Minimum & 3 & -0.042 & -0.005 & +88.1 \\
\hline & Mean value & - & 0.001 & 0.042 & +4100 \\
\hline \multirow{4}{*}{$C_{m}$} & Maximum & 3 & 0.056 & 0.049 & -12.5 \\
\hline & \multirow{2}{*}{ Minimum } & -1 & -0.179 & - & - \\
\hline & & 0 & - & -0.298 & - \\
\hline & Mean value & - & -0.047 & -0.027 & -42.6 \\
\hline
\end{tabular}

TABLE 11: The maximum and minimum of the car aerodynamical coefficients.

\begin{tabular}{|c|c|c|c|c|c|}
\hline & & Position & Unoptimized & Optimized & Optimizing rate (\%) \\
\hline \multirow{3}{*}{$C_{d}$} & Maximum & 3.6 & 0.546 & 0.527 & -3.5 \\
\hline & Minimum & -1 & 0.230 & 0.213 & -7.4 \\
\hline & Mean value & - & 0.331 & 0.327 & -1.2 \\
\hline \multirow{3}{*}{$C_{s}$} & Maximum & 0 & 0.171 & 0.147 & -14.0 \\
\hline & Minimum & 3.6 & -0.328 & -0.313 & -4.6 \\
\hline & Mean value & - & -0.041 & -0.041 & 0 \\
\hline \multirow{3}{*}{$C_{l}$} & Maximum & 2 & -0.018 & -0.022 & -22.2 \\
\hline & Minimum & 3.6 & -0.224 & -0.255 & -13.8 \\
\hline & Mean value & - & -0.064 & -0.071 & -10.9 \\
\hline \multirow{3}{*}{$C_{\mathrm{pm}}$} & Maximum & -2 & -0.104 & -0.098 & +5.8 \\
\hline & Minimum & 3.6 & -1.314 & -1.494 & -13.7 \\
\hline & Mean value & - & -0.408 & -0.428 & -4.9 \\
\hline \multirow{3}{*}{$C_{m}$} & Maximum & 3.6 & 1.826 & 1.913 & +4.8 \\
\hline & Minimum & 0 & -0.386 & -0.348 & -9.8 \\
\hline & Mean value & - & 0.328 & 0.332 & +1.2 \\
\hline
\end{tabular}

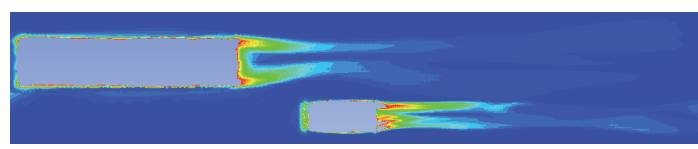

(a) Without optimization

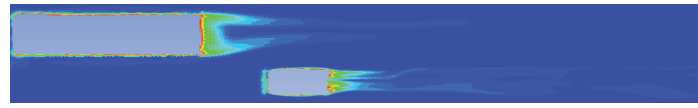

(b) Optimized

FIGURE 25: The vorticity contours in Position -1 during the overtaking maneuvers.

cylinders are opposite to the flow directions in these regions, which decelerates the velocity of the separation flow from
TABLE 12: Boundary conditions.

\begin{tabular}{lc}
\hline Inlet & Velocity inlet, $V_{\infty}=35 \mathrm{~ms}^{-1}$ \\
Outlet & Pressure outlet, $P=0 \mathrm{~Pa}$ \\
Floor & Translational moving wall, $V=30 \mathrm{~ms}^{-1}$ \\
Roof & Symmetry \\
Upper cylinder & Rotating wall, $V=-293 \mathrm{rad} / \mathrm{s}$ \\
Lower cylinder & Rotating wall, $V=1241 \mathrm{rad} / \mathrm{s}$ \\
Bus & Stationary wall \\
\hline
\end{tabular}

the upper and lower surface and changes the direction of the flow. After the simulation tests and mathematical analysis, the optimal speeds of cylinders are calculated at different velocities of the bus, and the optimizing effect of vehicle fuel economy is verified. Then, the subsequent simulations 


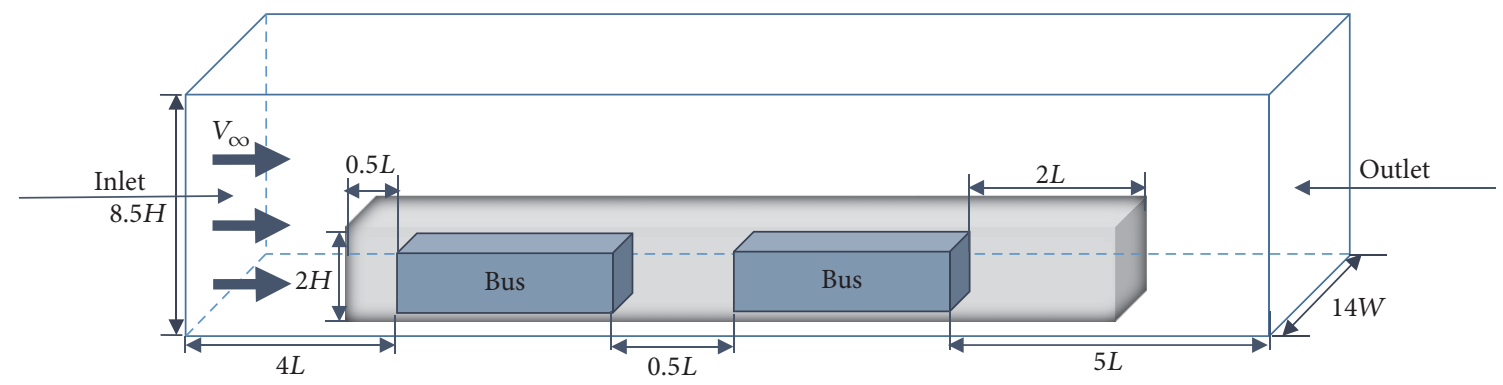

FIGURE 26: The physical model of platoon.

TABLE 13: The aerodynamic coefficients of both buses in platoon driving.

\begin{tabular}{lcccccc}
\hline & $C_{d}$ of front bus & $C_{d}$ of back bus & $C_{l}$ of front bus & $C_{l}$ of back bus & $C_{\mathrm{pm}}$ of front bus & $C_{\mathrm{pm}}$ of back bus \\
\hline Original & 0.428 & 0.376 & -0.154 & -0.025 & 0.138 & 0.213 \\
Optimized & 0.158 & 0.355 & -0.635 & -0.101 & 0.331 & 0.219 \\
Difference & $-63.1 \%$ & $-39.7 \%$ & $312.3 \%$ & $304.0 \%$ & $139.9 \%$ & $2.8 \%$ \\
\hline
\end{tabular}

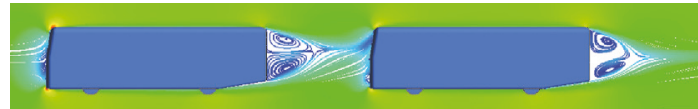

(a) Without optimization

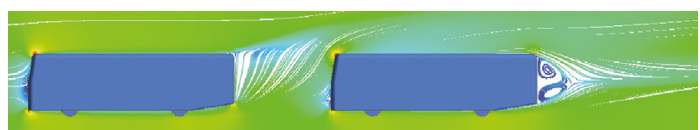

(b) Optimized

FIGURE 27: The streamline on the longitudinal symmetry plane in platoon.

testify the applicability of this optimization in crosswind driving, overtaking maneuvers, and platoon driving. The aerodynamic performances after optimization are all better than those without optimization under different conditions discussed above. Furthermore, this method optimizes not only the flow fields of the bus with the rotating cylinders but also the interactive vehicles without the rotating cylinders in the driving route, such as the overtaking vehicle, and the back vehicle in platoon. In conclusion, this method to optimize the wake flow of the vehicles can effectively improve the aerodynamic performance, the handling stability, and the fuel economy.

\section{Conflicts of Interest}

The authors declare that there are no conflicts of interest regarding the publication of this paper.

\section{Acknowledgments}

The authors would like to acknowledge Jilin Provincial Science \& Technology Development Program (20160101280JC) for supporting this study.

\section{References}

[1] H. Ouyang, Z. Zhang, P. Wu et al., "Wind Tunnel Experiment for Optimizing JT6120 Bus Aerodynamic Characteristics," Automotive Engineering, vol. 22, no. 3, pp. 171-175, 2000.

[2] J.-F. Beaudoin and J.-L. Aider, "Drag and lift reduction of a 3D bluff body using flaps," Experiments in Fluids, vol. 44, no. 4, pp. 491-501, 2008.

[3] Z. Wu, Q. Wei, K. Seizo et al., "The effect of length and inclined angle of air deflectors on reducing drag of large bluff-end vehicles," Automotive engineering, vol. 6, pp. 634-637, 2003.

[4] D. Geropp and H.-J. Odenthal, "Drag reduction of motor vehicles by active flow control using the Coanda effect," Experiments in Fluids, vol. 28, no. 1, pp. 74-85, 2001.

[5] E. Konstantinidis and D. Bouris, "The effect of nonharmonic forcing on bluff-body aerodynamics at a low Reynolds number," Journal of Wind Engineering and Industrial Aerodynamics, vol. 98, no. 6-7, pp. 245-252, 2010.

[6] Y. Zhuang, X. Sun, D. Huang, and G. Wu, "Numerical study on aerodynamic performances of the wind turbine rotor with leading-edge rotation," Journal of Renewable and Sustainable Energy, vol. 4, no. 6, Article ID 063103, 2012.

[7] Y.-Y. Zhang, D.-G. Huang, X.-J. Sun, and G.-Q. Wu, "Exploration in optimal design of an airfoil with a leading edge rotating cylinder," Journal of Thermal Science, vol. 19, no. 4, pp. 318-325, 2010.

[8] M. Lopes, D. Welsh, R. Gates et al., "The effects of a leading edge rotating cylinder on the performance of a NACA 0015 airfoil at high angles of attack," in Proceedings of the AIAA Atmospheric Flight Mechanics Conference - SciTech Forum and Exposition 2014, National Harbor, Maryland, Md, USA, January 2014.

[9] A. B. M. Badry, Y.-J. Lee, W.-T. Chong et al., "Numerical analysis of the effect of vortex control mechanism on longitudinal aerodynamics of lifting body," Aerospace Science and Technology, vol. 30, no. 1, pp. 232-238, 2013.

[10] J. Hoffman, B. Martindale, S. Arnette, J. Williams, and S. Wallis, "Effect of test section configuration on aerodynamic drag measurements," SAE Technical Papers, 2001.

[11] V. T. Shekar, A. Thuraimoni, S. Reddy, and A. Cherukuri, "A holistic approach to aerodynamics of intercity and interurban buses," SAE Technical Papers, vol. 1, 2014. 
[12] L. Fu and X. Liu, "A Study on the wake structure of typical automobile shapes," Automotive Engineering, vol. 18, no. 6, pp. 343347, 1996.

[13] J. Nocedal and S. J. Wright, Numerical Optimization, Springer Science+Business Media, Inc., 1999.

[14] W. Winn, Introduction to understandable physics: Volume IMechanics, AuthorHouse, 2010.

[15] S. Yang, S. Feng, S. Wang et al., "Instability of aluminum honeycomb sandwich panel under blast loading," Chinese Journal of High Pressure Physics, vol. 31, no. 2, pp. 193-201, 2017.

[16] D. Halliday and R. Resnick, Fundamentals of Physics, John Wiley Sons, Inc., 1970. 


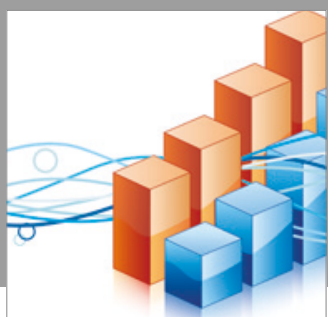

Advances in

Operations Research

vatersals

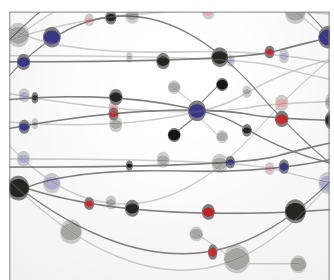

\section{The Scientific} World Journal

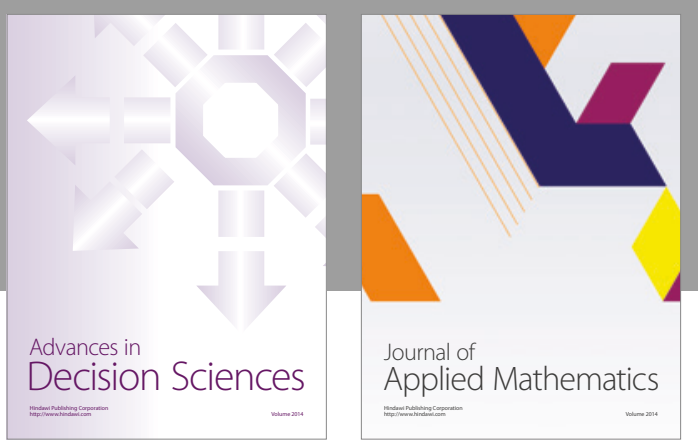

Algebra

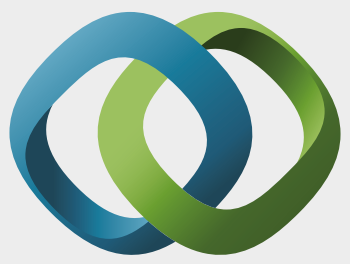

\section{Hindawi}

Submit your manuscripts at

https://www.hindawi.com
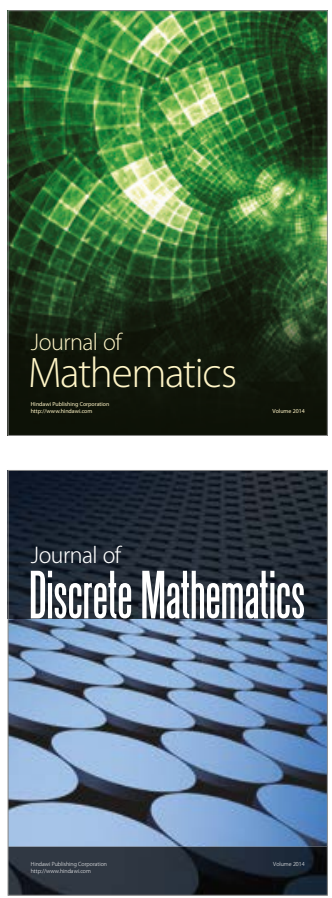



Mathematical Problems in Engineering
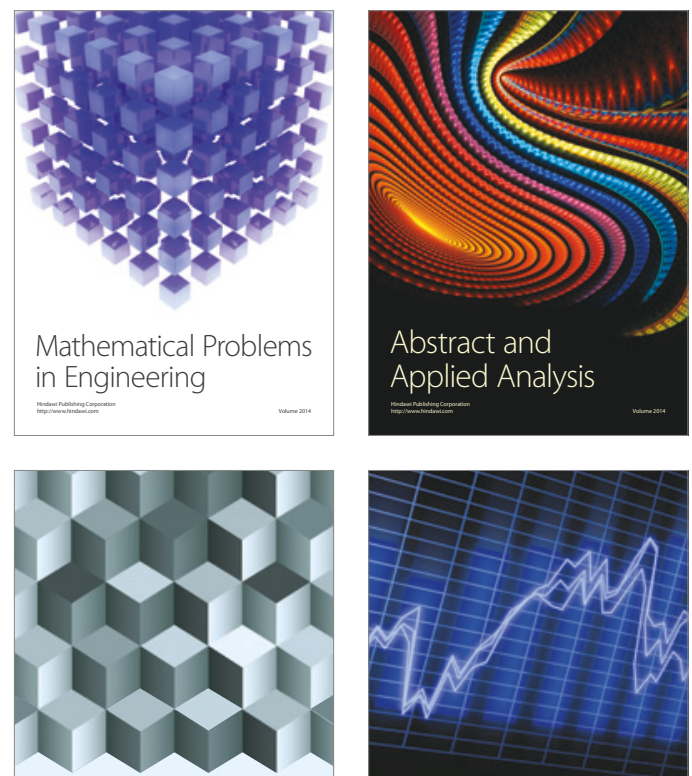

Journal of

Function Spaces



Probability and Statistics
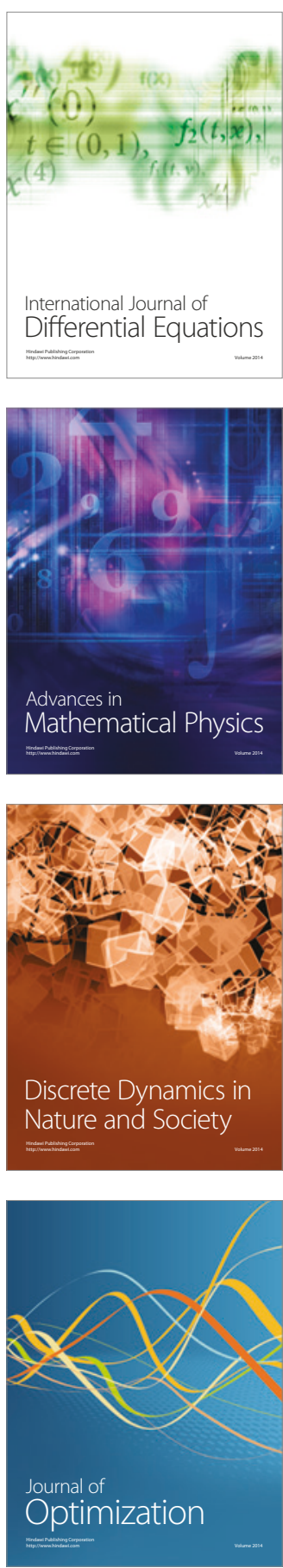